\title{
Genetic variation in recombination in Drosophila. II. Genetic analysis of a high recombination stock
}

\author{
Brian Charlesworth and \\ Deborah Charlesworth
}

School of Biological Sciences, University of Sussex, Brighton BN1 9QG, UK.*

The difference in $G l-S b$ recombination frequency between two stocks of Drosophila melanogaster, $\mathrm{H}$ and $\mathrm{C}$, has been analysed genetically. (The $\mathbf{H}$ stock was obtained by artificial selection for increased recombination.) Chromosome substitution experiments show that all three major chromosome contain genes which contribute to the H-C difference, and that there are significant interactions between the genes on different chromosomes. In particular, the $H \mathbf{2 n d}$ chromosome increases recombination on a background of homozygous $H$ and $X$ and $3 r d$ chromosomes, but reduces it if either the $\mathrm{X}$ or 3 rd is made homozygous for $\mathrm{C}$. The $\mathbf{H} \mathbf{X}$ chromosome exhibits partial or complete dominance over $\mathrm{C}$, depending on the genetic background, while the $H$ 2nd and 3rd chromosomes have dominant effects. Mapping experiments show that at least two recombination genes are located on chromosome 3 , one between $h$ and $G l$, the other to the right of $s t$, probably between $s t$ and $s r$. Previous data suggest that the $X$ and 2 nd chromosome effects are each contributed by single genes or tightly-linked gene complexes. These results are discussed in relation to previous work on the genetics of recombination, and to the patterns of response to selection described in the accompanying paper.

\section{INTRODUCTION}

In the accompanying paper (Charlesworth and Charlesworth, 1985), we described the results of artificial selection on recombination in female Drosophila melanogaster. We also presented the results of some genetic studies of the difference between a line $(\mathrm{H})$, which had responded to selection for increased recombination between the $3 \mathrm{rd}$ chromosome markers $G l$ and $S b$, and an unselected control stock (C). The genetic background of each of these stocks was derived largely from an outbred population (IV), founded from wild-caught flies. These genetic studies suggested that all three major chromosomes contributed to the difference in recombination frequency. A small reciprocal effect was shown to be controlled by the grandmaternal nuclear genotype.

In this paper, we extend these genetic studies by examining the individual contributions of the $\mathrm{X}$, 2nd and 3 rd chromosomes to the differences between the $\mathrm{H}$ and $\mathrm{C}$ stocks, both in homozygous and heterozygous states. Interactions between these chromosomes are also studied. An attempt

* Present address: Department of Biology, University of Chicago, 1103 E. 57th St., Chicago, IL 60637, U.S.A. to localise the 3 rd chromosome genes affecting the recombination effect is described. The results are discussed in relation to previous work on the genetics of recombination.

\section{MATERIALS AND METHODS}

All experimental procedures were as described in the accompanying paper (Charlesworth and Charlesworth, 1985), except that some experiments involved the measurement of recombination frequencies using vial-reared progenies. For such experiments, 2-pair matings were set up in $3^{\prime \prime} \times 1^{\prime \prime}$ vials, and the emerging progeny were counted three times over an 8-day period.

\section{Chromosome substitutions}

The stocks used in the assays of individual chromosome effects described in the third section were constructed from the isogenic $\mathrm{H}$ (high) and $\mathrm{C}$ (control) stocks described in the fourth section of Charlesworth and Charlesworth (1985), using the balancers described in that paper. Details of the breeding procedure will be omitted here, but can 
be supplied on request. The genotypes of the stocks are shown in table 1. Each stock was tested for secondary non-disjunction of the $X$ chromosome as described in the fourth section of Charlesworth and Charlesworth (1985), with negative results. This indicates that the $\mathrm{X}$ chromosome of each stock can be reliably regarded as being derived from the $\mathrm{H}$ or $\mathrm{C}$ stocks as appropriate.

\section{Mapping experiments}

These involved the construction of recombinant chromosomes between the $\mathrm{Gl}$ chromosome 3 and the multiply-marked third chromosome rucuca, supplied by Dr D. Ish-Horowicz of the Imperial Cancer Research Fund. This contains the markers $r u(0 \cdot 0), h(26 \cdot 5)$, th (43.2), st (44.0), cu (50.0), $s r(62 \cdot 0), e(70 \cdot 7)$ and $c a(100 \cdot 7)$. The wing mutant $c u$ was not followed in these experiments, as it proved difficult to classify reliably. In order to construct recombinant chromosomes, rucuca was transferred onto a background of $\mathrm{H} \mathrm{X}$ and 2 nd chromosomes. Individual recombinant chromosomes carrying $\mathrm{Gl}$ were isolated from crosses between this rucuca stock and $\mathrm{H} \mathrm{H} \mathrm{Gl} l_{\mathrm{H}}$, using the following mating scheme (which shows the isolation of an ru $h \mathrm{Gl}$ chromosome)

$$
\begin{aligned}
& q \frac{G l}{\text { rucuca }} \times \frac{T M 6}{\text { rucuca }} \delta \\
& q \frac{T M 6}{S b} \times \frac{r u h G l}{\text { rucuca }} \text { o } \\
& q \frac{T M 6}{r u h G l} \times \frac{T M 6}{r u h G l} \delta
\end{aligned}
$$

The recombinant chromosomes were maintained balanced over TM6 in the usual way, and their frequencies of $G l-S b$ recombination measured by crossing to $\mathrm{H} \mathrm{H} S b$ females and scoring the progenies of vial matings of these with IV males. The linkage relationships of the markers used in these experiments are shown in fig. 1 .

\section{Statistical procedures}

Tests of significance were carried out using the angular transforms of recombination frequencies. Comparisons of means of different genotypes were made by $t$-tests (individual culture values were not weighted by numbers of flies per culture, since there was evidence for a substantial non-binomial component to the error variance). The standard errors attached to the untransformed means given
Table 1 Chromosome substitution stocks

The following isogenic chromosome substitution stocks were constructed using the $\mathrm{H} \mathrm{H} \mathrm{H}_{\mathrm{H}}, \mathrm{H} \mathrm{HS} b_{\mathrm{H}}, \mathrm{C} \mathrm{C} G l_{\mathrm{C}}$ and $\mathrm{CC} S b_{\mathrm{C}}$ isogenic stocks described by Charlesworth and Charlesworth (1985). The constitutions of the X, 2nd and 3 rd chromosomes, with respect to their origin from the high recombination $(\mathrm{H})$ or control $(\mathrm{C})$ stocks, are shown in order; $G l$ and $S b$ 3rd chromosomes are distinguished from each other. In each case, chromosome 3 is balanced over the TM6 multiply-inverted 3rd chromosome. Each stock was isolated in two independent experiments, in order to guard against balancer breakdowns and other

\begin{tabular}{|c|c|c|c|c|}
\hline \multicolumn{5}{|c|}{ lst chromosome substitutions } \\
\hline $\mathrm{H} \mathrm{C} G l_{\mathrm{C}}$ & $\mathrm{HCS} b_{\mathrm{C}}$ & $\mathrm{C} \mathrm{H} G l_{\mathrm{H}}$ & $\mathrm{CHS} b_{\mathrm{H}}$ & \\
\hline \multicolumn{5}{|c|}{ 2nd chromosome substitutions } \\
\hline $\mathrm{CH} G l_{\varsigma}$ & $\mathrm{CH} S b_{C}$ & $\mathrm{HC} G l_{\mathrm{H}}$ & $\mathrm{HCS} b_{\mathrm{H}}$ & \\
\hline \multicolumn{5}{|c|}{ 3rd chromosome substitutions } \\
\hline $\mathrm{C} \mathrm{C} G l_{\mathrm{H}}$ & C C $S b_{\mathrm{H}}$ & $\mathrm{HHGl}$ & $\mathrm{H} \mathrm{HS} S b_{C}$ & \\
\hline $\mathbf{0}$ & 26 & 114344465862 & 71 & 101 \\
\hline
\end{tabular}
accidents; the two isolates are designated as E1 and E2 respectively

Figure 1 Approximate map positions of the 3rd chromosome markers used in the mapping experiments are shown

in the text and tables were calculated directly from the corresponding sample variances of the untransformed data, except where otherwise stated.

\section{EFFECTS OF WHOLE CHROMOSOMES}

In this section, we shall describe the results of measurements of the frequency of recombination between $G l$ and $S b$ in stocks differing with respect to their constitution for various combinations of chromosomes from the $\mathrm{H}$ and $\mathrm{C}$ stocks. Except where otherwise indicated, $G I_{-} S b$ recombination was assayed in bottle crosses, as described by Charlesworth and Charlesworth (1985, second section).

\section{Homozygous effects of the different chromosomes: methods}

The homozygous effects of the different chromosomes were determined by comparing the frequencies of $G l-S b$ recombination in all eight possible combinations of $\mathrm{H}$ versus $\mathrm{CX}, 2 \mathrm{nd}$ and $3 \mathrm{rd}$ chromosomes, using the original isogenic $\mathrm{H}$ and $\mathrm{C}$ lines and the substitution stocks of table 1 . The 
Table 2 Effects of the individual chromosomes on $G l-S b$ recombination

\begin{tabular}{|c|c|c|c|c|c|c|c|}
\hline \multicolumn{4}{|c|}{ Genotype } & \multicolumn{2}{|c|}{$C y^{+}$females } & \multicolumn{2}{|c|}{$C y$ females } \\
\hline Chr: & 1 & 2 & 3 & Mean \pm S.E. & No. of cultures & Mean \pm S.E. & No. of cultures \\
\hline & $\mathrm{C}$ & $\mathrm{C}$ & $\mathrm{C}$ & $0 \cdot 130 \pm 0 \cdot 005$ & 22 & $0 \cdot 160 \pm 0 \cdot 007$ & 26 \\
\hline & $\mathrm{H}$ & $\mathrm{C}$ & $\mathrm{C}$ & - & - & $0 \cdot 210 \pm 0.014$ & 10 \\
\hline & $\mathrm{C}$ & $\mathrm{H}$ & $\mathrm{C}$ & $0.095 \pm 0.004$ & 9 & $0.151 \pm 0.004$ & 16 \\
\hline & $\mathrm{C}$ & $\mathrm{C}$ & $\mathrm{H}$ & $0.152 \pm 0.007$ & 13 & $0 \cdot 185 \pm 0.006$ & 19 \\
\hline & $\mathrm{H}$ & - $\mathrm{H}$ & $\mathrm{C}$ & $0.151 \pm 0.024$ & 7 & $0 \cdot 172 \pm 0.008$ & 18 \\
\hline & $\mathrm{H}$ & $\mathrm{C}$ & $\mathrm{H}$ & - & - & $0 \cdot 189 \pm 0.009$ & 8 \\
\hline & $\mathrm{C}$ & $\mathrm{H}$ & $\mathrm{H}^{*}$ & $0 \cdot 110 \pm 0 \cdot 005$ & 14 & $0 \cdot 165 \pm 0 \cdot 009$ & 18 \\
\hline & $\mathrm{H}$ & $\mathrm{H}$ & $\mathrm{H}$ & $0.170 \pm 0.027 \dagger$ & 11 & $0.259 \pm 0.010$ & 29 \\
\hline
\end{tabular}

* These results may be artefactual. See text for explanation.

$\dagger$ This, unfortunately, has an unusually high sampling variance, and the low mean is probably attributable to a statistical fluctuation. The results of previous measurements suggest a value of 0.21 as more representative.

results of these experiments, which were carried out in the autumn of 1980 , are shown in table 2 . (Note that the designation $\mathrm{C}$ or $\mathrm{H}$ for the $3 \mathrm{rd}$ chromosome means that recombination was measured in $G l_{C} / S b_{\mathrm{C}}$ or $G l_{\mathrm{H}} / S b_{\mathrm{H}}$ females respectively.) With the exception of the $\mathrm{HCC}$ stock, results from the independently extracted substitution lines (E1 and E2) agreed, and have been pooled. Reciprocal crosses (i.e., $\varsubsetneqq G l \times S b$ ô versus $\uparrow S b \times G l$ ठ) have also been pooled, as no differences were detected.

Recombination in females heterozygous for the 2nd chromosome balancer $S M 1$ (which carries the marker $C y$ ), and in females homozygous for wildtype, was measured separately. These females are designated $C y$ and $C y^{+}$in table 2. It is well known that heterozygosity for an inversion on one chromosome increases the frequency of crossing over in other chromosomes in Drosophila (Lucchesi and Suzuki, 1968), and this is seen clearly in table 2 . The ratio of the recombination frequency in $C y$ to that in $C y^{+}$females varies from 1.59 to 1.21 , with a mean of 1.36 . It is noteworthy that two stocks, $\mathrm{H} \mathrm{C} \mathrm{C}$ and $\mathrm{H} \mathrm{C} \mathrm{H}$, are sterile (this was found to be due to both male and female sterility), so that recombination could be measured only in $C y$ females in these stocks. This sterility presumably is due to an interaction between the $\mathrm{H} \mathrm{X}$ and the $\mathrm{C} 2$ nd chromosomes, such that $\mathrm{Gl} / \mathrm{Sb}$ flies are sterile on an $\mathrm{H} \mathrm{C}$ background. Curiously, $T M 6 / G l$ and $T M 6 / S b$ flies are fertile on this background.

The line $\mathrm{H} \mathrm{C} \mathrm{C} \mathrm{(E1)} \mathrm{had} \mathrm{a} \mathrm{significantly} \mathrm{higher}$ recombination frequency than its E2 counterpart $(0.210 \pm 0.014$ versus $0.164 \pm 0.007)$, suggesting that some error had occurred in the breeding programme. The most likely error is a crossover between the 3 rd chromosome balancer TM 6 and the $G l$ or $S b$ chromosomes in the E2 line, introducing a rearrangement which reduces crossing over between $G l$ and $S b$. Any effect of chromosome 2 can be excluded, since recombination was measured in flies heterozygous for the highly efficient $S M 1$ balancer. There was no evidence that the $\mathrm{X}$ chromosome had acquired any markers from the $F M 7$ balancer during the breeding programme. Furthermore, as we will describe in the next paper in this series, the $\mathrm{X}$ chromosome from the El $S b$ stock increases recombination uniformly along chromosome 3 , and its effect is similar to that of the $\mathrm{X}$ chromosome from the $\mathrm{H} \mathrm{C} \mathrm{H}$ stock. These observations are inconsistent with the possibility that the $\mathrm{X}$ chromosome in the $\mathrm{HCC}$ stock was segregating for a inversion derived from $F M 7$, since this would have specifically increased recombination in the centromeric region of chromosome 3 (Lucchesi and Suzuki, 1968). Since the H versus $\mathrm{C}$ comparison using the $\mathrm{E} 2$ stock was only barely significant statistically, and could not be confirmed in later experiments, it seems reasonable to take the $\mathrm{E} 1$ lines as representative of the true effect of the $\mathrm{H} \mathrm{X}$ chromosome on a $\mathrm{C}$ background, and this is the value given in table 2 .

\section{Homozygous chromosome effects: results}

It is clear from table 2 that the different chromosomes show considerable deviations from additivity of effects. The following features of interest may be noted.

(a) Both the $\mathrm{HX}$ and $\mathrm{H}$ 3rd chromosomes increase recombination when present on a $\mathrm{C}$ background for the other chromosomes. However, $\mathrm{H} \mathrm{C} \mathrm{H}$ shows no increases above $\mathrm{H} \mathrm{C} \mathrm{C} \mathrm{or} \mathrm{C} \mathrm{C} \mathrm{H}$ (only $C y$ females can be used for this comparison, of course).

(b) Conversely, both the CX and C 3rd chromosomes have a strong effect in reducing recombination when placed on an $\mathrm{H}$ background for the other chromosomes. Paradoxically, $\mathrm{CH} \mathrm{H}$ 
appears to have as low a value as C C C, although this may be an artefact as discussed below.

(c) The $\mathrm{H}$ 2nd chromosome reduces recombination on a background of $\mathrm{CX}$ or $\mathrm{C} 3$ rd chromosomes, but increases recombination when both $\mathrm{X}$ and $3 \mathrm{rd}$ chromosomes are $\mathrm{H}$. These effects are both apparent in $C y$ females, suggesting that the 2 nd chromosome effect is due to a dominant gene or genes.

\section{Heterozygous effects of the different chromosomes}

The laborious nature of the measurements of recombination frequencies precluded an analysis of the effect of each chromosome when heterozygous $(\mathrm{H} / \mathrm{C})$ in all possible backgrounds. Instead, a series of experiments were performed in the spring of 1981, in which a limited range of genotypes was measured, using the same methods as above.

\section{Heterozygous effect of the $X$ chromosome on a $C$ background}

The genotypes assayed, and their recombination frequencies, are shown in table 3 . The clearest results are for $C y$ females, where it is apparent that $\mathrm{H} / \mathrm{C}$ shows an increase over $\mathrm{C} / \mathrm{C}$ on a back- ground of $\mathrm{C} 2$ nd and 3 rd chromosomes. The cross

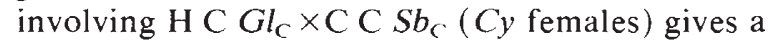
significantly higher recombination frequency than the reciprocal cross $\left(t_{28}=3 \cdot 13, \mathrm{p}<0 \cdot 01\right)$. This may be a statistical fluke, since no such effect is apparent in non- $C y$ females, where there is nevertheless a significant effect of $\mathrm{H} / \mathrm{C}$ compared with $\mathrm{C} / \mathrm{C}$. The average over both classes of $\mathrm{H} / \mathrm{C}$ flies suggests intermediate rather than full dominance for the $\mathrm{HX}$ chromosome effect in $C y$ flies.

\section{Heterozygous effect of the $X$ chromosome on an $\mathrm{H}$ background}

A similar set of experiments was carried out on a background of $\mathrm{H}$ 2nd and 3 rd chromosomes, with the results shown in table 4 . These are somewhat difficult to interpret, as the results of different crosses which should yield the same genotypes are not consistent. In the first place, the El and E2 C H H genotypes differ significantly, E2 being higher than El. A similar difference was found in the earlier results reported in table 2 , but was not statistically significant. Secondly, H/C genotypes in which the $\mathrm{Gl}$ chromosome is derived from $\mathrm{H} \mathrm{H} \mathrm{H} \mathrm{(crosses} \mathrm{B)} \mathrm{tend} \mathrm{to} \mathrm{have} \mathrm{significantly} \mathrm{higher}$ recombination frequencies than when $G l$ comes from $\mathrm{CH} \mathrm{H}$ (crosses A).

Table 3 Heterozygous effects of the X chromosome on $G l-S b$ recombination on a C background

\begin{tabular}{|c|c|c|c|c|}
\hline \multirow[b]{2}{*}{ Genotype } & \multicolumn{2}{|c|}{$C y^{\prime}$ females } & \multicolumn{2}{|c|}{$C y$ females } \\
\hline & Mean \pm S.E. & No. of Cultures & Mean \pm S.E. & No. of Cultures \\
\hline $\mathrm{CCC}$ & $0 \cdot 103 \pm 0 \cdot 005$ & 10 & $0 \cdot 114 \pm 0 \cdot 004$ & 13 \\
\hline $\mathrm{HCC}$ & - & - & $0.178 \pm 0.006$ & 12 \\
\hline $\begin{array}{l}\mathrm{H} / \mathrm{C} \mathrm{C} \mathrm{C} \\
\quad\left(\mathrm{HCS} S b_{\mathrm{C}} \times C \mathrm{C} G l_{\mathrm{C}}\right)\end{array}$ & $0 \cdot 125 \pm 0.005$ & 10 & $0 \cdot 136 \pm 0 \cdot 005$ & 18 \\
\hline $\begin{array}{l}\mathrm{H} / \mathrm{C} \mathrm{C} \mathrm{C} \\
\quad\left(\mathrm{HCCl} l_{c} \times C \mathrm{C} S b_{c}\right)\end{array}$ & $0 \cdot 119 \pm 0 \cdot 005$ & 10 & $0 \cdot 161 \pm 0 \cdot 006$ & 12 \\
\hline
\end{tabular}

Table 4 Heterozygous effect of the X chromosome on $G l-S b$ recombination on an $\mathrm{H}$ background

\begin{tabular}{llcll}
\hline Genotype & \multicolumn{2}{c}{$C y^{+}$females } & \multicolumn{2}{c}{$C y$ females } \\
& Mean \pm S.E. & No. of cultures & Mean \pm S.E. & No.of cultures \\
\hline C H H (E1) & $0.083 \pm 0.003$ & 27 & - & - \\
C H H (E2) & $0 \cdot 113 \pm 0.007$ & 9 & - & - \\
C/H H H (E1A) & $0.094 \pm 0.003$ & 27 & - & - \\
C/H H H (E1B) & $0 \cdot 141 \pm 0.005$ & 12 & $0.164 \pm 0.005$ & 18 \\
C/H H H (E2A) & $0 \cdot 115 \pm 0.005$ & 8 & $0.234 \pm 0.006$ & 25 \\
C/H H H (E2B) & $0.127 \pm 0.007$ & 5 & $0.222 \pm 0.011$ & 16 \\
H H H & $0.147 \pm 0.005$ & 20 & & - \\
\hline
\end{tabular}

E1 and E2 refer to the independently constructed $\mathrm{C} \mathrm{H} \mathrm{H} \mathrm{lines;} \mathrm{A}$ and $\mathrm{B}$ refer to genotypes from crosses of the type $\mathrm{C} \mathrm{H} G l_{\mathrm{H}} \times \mathrm{H} \mathrm{HS} b_{\mathrm{H}}$ and $\mathrm{C} \mathrm{H} \mathrm{Sb} b_{\mathrm{H}} \times \mathrm{H} \mathrm{H} G l_{\mathrm{H}}$ respectively.

The tests on the $C y$ females were carried out one year after the tests on the $C y^{+}$females. 
The most likely interpretation is that the $G l$ chromosome in both the $\mathrm{CH} \mathrm{HE} 1$ and E2 stocks acquired some recombination-restricting genetic material from TM6 during the course of the construction of these stocks, to a different extent in the $\mathrm{E} 1$ and $\mathrm{E} 2$ lines. If this is so, the assays on the $\mathrm{C} \mathrm{H} \mathrm{H}$ lines are worthless, and their unusually low values (seen in both tables 2 and 4 ) are explained. The appropriate test for the heterozygous effect of the $\mathrm{HX}$ chromosome is thus to compare $\mathrm{H} \mathrm{H} \mathrm{H}$ with $\mathrm{C} / \mathrm{H} \mathrm{HH}$ (B) in table 4 ; the $C y$ and $\mathrm{Cy}^{+}$ results suggest almost complete dominance of the $\mathrm{HX}$ gene or genes over those of the $\mathrm{C}$ chromosome. This is consistent with the results for the effect on the $\mathrm{C}$ background described above.

\section{Heterozygous effect of 2nd chromosome (C background)}

This was tested as shown in table 5, using non-Cy females only. It is clear that the $\mathrm{H} 2$ nd chromosome is effectively dominant in reducing crossing over on this background. Time unfortunately did not permit a study of this effect on an $\mathrm{H}$ background, but the results of table 2 strongly suggest a dominant effect of the $\mathrm{H}$ chromosome 2 , since it

Table 5 Heterozygous effect of the 2 nd chromosome on $\mathrm{Gl}-\mathrm{Sb}$ recombination on a $C$ background

\begin{tabular}{llc}
\hline Genotype & Mean \pm S.E. & No. of cultures \\
\hline C C C & $0 \cdot 104 \pm 0 \cdot 013$ & 6 \\
C H C & $0 \cdot 079 \pm 0 \cdot 004$ & 12 \\
C C / H C & $0 \cdot 082 \pm 0.003$ & 28 \\
\hline
\end{tabular}

for the $\mathrm{X}$ chromosome and simultaneously either $\mathrm{Cy} / \mathrm{C}$ or $\mathrm{Cy} / \mathrm{H}$ for the 2 nd chromosome, on a background of $\mathrm{H} 3$ rd chromosomes. No significant diflerence was detectable between $\mathrm{Cy} / \mathrm{C}$ and $\mathrm{Cy} / \mathrm{H}$ flies, and the pooled recombination frequency for the $\mathrm{X}$ chromosome heterozygotes was $0 \cdot 252 \pm 0.0067$ (15 cultures), compared with $0 \cdot 229 \pm 0.007$ ( 10 cultures) and $0 \cdot 247 \pm 0.012$ for $C$ and $\mathrm{HX}$ chromosome homozygotes. This again suggests a dominant effect of the $\mathrm{H} \mathrm{X}$ chromosome.

\section{Heterozygous effect of 3rd chromosome (C background)}

Table 6 displays the relevant data, where flies heterozygous for $S b_{\mathrm{H}}$ and $G l_{\mathrm{H}} / S b$ have been distinguished from each other. As suggested by the results of Charlesworth and Charlesworth (1984, section 4) on the Fl's between the isogenic $\mathrm{H}$ and C stocks, the $S b_{\mathrm{H}}$ chromosome does not appear to have any effect, and the recombination frequency of $G l_{\mathrm{H}} / S b_{\mathrm{H}}$ is the same as that of $G l_{\mathrm{H}} / S b_{\mathrm{C}}$.

\section{Heterozygous effect of 3rd chromosome ( $H$ background)}

Similar experiments using a background of $\mathrm{HX}$ and 2nd chromomes completely confirm this conclusion. The mean of $G l_{C} / S b_{\mathrm{H}}$ is $0 \cdot 161 \pm 0 \cdot 004$, and that of $G l_{\mathrm{H}} / S b_{\mathrm{C}}$ is $0 \cdot 246 \pm 0.005$, compared with values of $0 \cdot 151 \pm 0.005$ for $G l_{\mathrm{C}} / S b_{\mathrm{C}}$ and $0 \cdot 228 \pm 0 \cdot 007$ for $G l_{\mathrm{H}} / S b_{\mathrm{H}}$ (all these values are for Cy females).

Table 6 Heterozygous effects of the 3 rd chromosome on $G l-S b$ recombination on a C background

\begin{tabular}{lcccc}
\hline Genotype & Mean \pm S.E. & $\begin{array}{c}C y^{+} \text {females } \\
\text { No. of cultures }\end{array}$ & Mean \pm S.E. & $\begin{array}{c}C y \text { females } \\
\text { No. of cultures }\end{array}$ \\
\hline $\mathrm{C} \mathrm{C} \mathrm{Gl} / S b_{\mathrm{C}}$ & $0 \cdot 104 \pm 0 \cdot 004$ & 9 & $0 \cdot 122 \pm 0 \cdot 005$ & 10 \\
$\mathrm{C} \mathrm{C} \mathrm{Gl} / S b_{\mathrm{H}}$ & $0 \cdot 120 \pm 0 \cdot 004$ & 13 & $0 \cdot 151 \pm 0 \cdot 006$ & 13 \\
$\mathrm{C} \mathrm{C} \mathrm{Gl} / S b_{\mathrm{H}}$ & $0 \cdot 103 \pm 0 \cdot 004$ & 19 & $0 \cdot 126 \pm 0 \cdot 004$ & 18 \\
$\mathrm{C} \mathrm{C} \mathrm{Gl} l_{\mathrm{H}} / S b_{\mathrm{C}}$ & $0 \cdot 128 \pm 0 \cdot 006$ & 17 & $0 \cdot 151 \pm 0 \cdot 005$ & 17 \\
\hline
\end{tabular}

significantly increased recombination when heterozygous with $C y$ on an $\mathrm{H} \mathrm{X}$ and $3 \mathrm{rd}$ chromosome background. (This effect was confirmed in some later experiments, which we will not report in detail.)

\section{Joint heterozygous effects of $X$ and 2 nd chromosomes}

An experiment was carried out to measure the recombination frequency of flies which were $\mathrm{H} / \mathrm{C}$

\section{Further analysis of the 3rd chromosome effect}

(a) A possible explanation of the apparent absence of effect of the $S b_{\mathrm{H}}$ chromosome is that the stocks carrying $S b_{\mathrm{H}}$ also contain a dominant factor that reduces crossing over, as a result of some error in the breeding programmes. This is extremely unlikely, since the difference between the $G l_{\mathrm{H}}$ and the $S b_{\mathrm{H}}$ chromosome is apparent in the $\mathrm{Fl}$ 's between the isngenic $\mathrm{HH} \mathrm{H}$ and $\mathrm{C} \mathrm{CC}$ stocks, and in both $\mathrm{C} \mathrm{C} \mathrm{H} / \mathrm{C}$ and $\mathrm{H} \mathrm{H} \mathrm{H} / \mathrm{C}$ flies. 
A direct test for this possibility seemed desirable, however, and was carried out by intercrossing $\mathrm{HHS} b_{\mathrm{H}}$ with $\mathrm{HHGl} l_{\mathrm{H}}$, and backcrossing the $T M 6 / G l_{\mathrm{H}}$ progeny male; to $\mathrm{HH} S b_{\mathrm{C}}$. The recombination frequencies i the resultant $G l_{\mathrm{H}} / S b_{\mathrm{C}}$ female progeny were the I compared to those of $G l_{\mathrm{H}} / S b_{\mathrm{C}}$ females from the i'l between $\mathrm{H} \mathrm{H} S b_{\mathrm{H}}$ and $\mathrm{HHGl} l_{\mathrm{H}}$. The respective mean recombination frequencies were $0 \cdot 156 \pm 0 \cdot 008$ and $0 \cdot 160 \pm 0 \cdot 009$. This excludes the hypothesis of some artefact due to other chromosomes.

Table 7 Effects of different 3 rd chromosomes on $s t-s r$ recombination in $\mathrm{Cy}$ females

\begin{tabular}{lcc}
\hline Genotype & Mean \pm S.F. & No. of cultures \\
\hline H H Gl $l_{H 1} /$ rucuca & $0.270 \pm 0.016$ & 13 \\
H H Sb $b_{H} /$ rucuca & $0.202 \pm 0.009$ & 13 \\
H H Gl $/$ rucuca (E1) & $0.189 \pm 0.015$ & 14 \\
H H Sb /rucuca (E1) & $0.183 \pm 0.010$ & 14 \\
H H Gl $/$ rucuca (E2) & $0.172 \pm 0.012$ & 8 \\
H H Sb / rucuca (E2) & $0.176 \pm 0.012$ & 10 \\
\hline
\end{tabular}

(b) The properties of the $S b_{\mathrm{H}}$ and $G l_{\mathrm{H}} 3 \mathrm{rd}$ chromosomes were further compared by examining their effects on recombination between the neighbouring $3 \mathrm{rd}$ chromosome recessive marker genes $s t$ and $s r$. To this end, the multiply-marked 3 rd chromosome rucuca was crossed onto a background of $\mathrm{H} \mathrm{X}$ and 2 nd chromosomes derived from the $\mathrm{H} \mathrm{H} \mathrm{Gl} l_{\mathrm{H}}$ stock. This stock was then crossed to $\mathrm{H} \mathrm{H} G l_{\mathrm{H}}$ and $\mathrm{H} \mathrm{H} S b_{\mathrm{H}}$ respectively, and $s t-s r$ recombination in $C y$ females was assayed in vial cultures by backcrosses to rucuca males from the original, unstandardised rucuca stock. The results are shown in table 7 (top). It is clear that $G l_{\mathrm{H}}$ causes a much higher frequency of $s t-s r$ recombination than does $S b_{\mathrm{H}}$. Since the interval $s t-s r$ overlaps $G l-S b$ (44-62 and 41-58, respectively) this gives an indication of the extent to which the $G l-S b$ recombination frequency is affected by $G l_{\mathrm{H}}$.

A similar experiment was carried out to compare the $G l_{C}$ and $S b_{C}$ chromosomes, by intercrossing the $\mathrm{HH}$ rucuca stock with $\mathrm{HHGl}_{C}$ and $\mathrm{H} \mathrm{H} S b_{\mathrm{C}}$ respectively. The results are shown in the bottom half of table 7, and indicate that $G l_{C}$ and $S b_{c}$. do not differ. These crosses were carried out over a month later than the previous set, so that the apparently low recombination frequencies compared with $S b_{\mathrm{H}}$ may not mean much.

\section{MAPPING EXPERIMENT}

\section{Methods}

An attempt was made to localise the high recombination gene or genes carried on chromosome 3, using recombinants between the $G l_{\mathrm{H}}$ and the multiply marked rucuca third chromosomes, as described in "Materials and Methods". The frequency of $G l-S b$ recombination was assayed in females heterozygous for $S M 1$, on a background of $\mathrm{HX}$ and 2nd chromosomes, for each recombinant chromosome. Owing to the necessity of scoring numerous replicates of each recombinant chromosome, only a limited number of recombinants could be characterised reasonably accurately. The assays of recombination extend over the period from December 1982 to September 1983; most recombinant chromosomes, together with two control chromosomes $\left(G l_{\mathrm{C}}\right.$ and $G l_{\mathrm{H}}$ on a background of $\mathrm{HX}$ and 2nd chromosomes), were assayed several times over this period; there was

Table $8 G l-S h$ recombination frequencies for $G l$ recombinant chromosomes

\begin{tabular}{|c|c|c|c|c|c|}
\hline Chromosome & $\begin{array}{l}\text { Mean recombination } \\
\text { frequency }(+ \text { S.F.. })\end{array}$ & $\begin{array}{l}\text { No. of } \\
\text { cultures }\end{array}$ & Chromosome & $\begin{array}{l}\text { Mean recombination } \\
\text { frequency }( \pm \text { S.E. })\end{array}$ & $\begin{array}{l}\text { No. of } \\
\text { cultures }\end{array}$ \\
\hline ruh Gl th st 1 & $0.285 \pm 0.031$ & 16 & Glsreca 31 & $0 \cdot 246 \pm 0 \cdot(022$ & 25 \\
\hline ru h $G l 35$ & $0 \cdot 260 \pm 0 \cdot 013$ & 79 & Glsreca 33 & $0 \cdot 242 \pm 0 \cdot 018$ & 39 \\
\hline ru h Gl 70 & $0 \cdot 239 \pm 0 \cdot 042$ & 7 & Glsreca 71 & $0 \cdot 235 \pm 0 \cdot 045$ & 6 \\
\hline ru h $G l 31$ & $0.238 \pm 0.016$ & 45 & Gl th st 72 & $0 \cdot 258 \pm 0 \cdot 013$ & 75 \\
\hline ru h Gl 10 & $0.233 \pm 0.014$ & 61 & Gl th st 71 & $0 \cdot 239 \pm 0 \cdot 014$ & 60 \\
\hline$r u h G l 1$ & $0 \cdot 230 \pm 0.016$ & 49 & Gl th st sr 71 & $0.230 \pm 0.013$ & 65 \\
\hline ruh Gl 19 & $0.222 \pm 0.016$ & 48 & Gl th st srecal & $0.229 \pm 0.013$ & 71 \\
\hline ruh $G l 14$ & $0.208+0.014$ & 54 & & & \\
\hline ruh $G l 7$ & $0.220 \pm 0.048$ & 5 & Gl st sre ca 72 & $(0 \cdot 199 \pm 0 \cdot(015$ & 46 \\
\hline $\operatorname{mihGl} 22$ & $0 \cdot 202 \pm 0 \cdot 018$ & 34 & Gl 41 & $0 \cdot 254 \pm 0 \cdot(018$ & 41 \\
\hline ruh Gl 34 & $0.193 \pm 0.018$ & 31 & Gl 76 & $0.260 \pm 0.028$ & 16 \\
\hline ruh Gl 16 & $0 \cdot 185 \pm 0 \cdot 032$ & 10 & $\mathrm{Gl}_{\mathrm{H}}$ & $0.266 \pm 0.035$ & 11 \\
\hline h $G l 72$ & $0.222 \pm 0.030$ & 48 & $G l_{C}$ & $0 \cdot 226 \pm 0 \cdot 007$ & 205 \\
\hline
\end{tabular}


no evidence for systematic variations between different dates of assay for the same chromosome in these data.

\section{Results}

The means and standard errors of the $G l-S b$ recombination frequencies of the recombinant chromosomes, together with the controls, are shown in table 8. A graphical display of the results for the chromosomes where more than 10 replicates were assayed is given in fig. 2. An anomaly in the

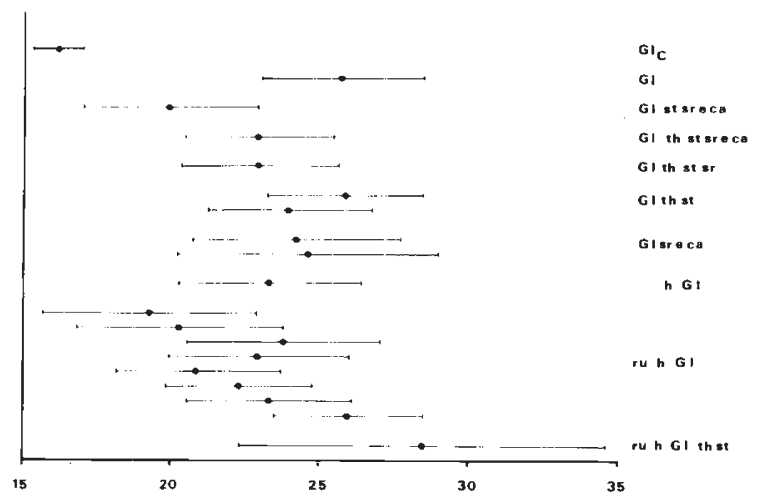

Figure 2 Means (dots) and 95 per cent confidence intervals (bars) for the $\mathrm{Gl}-\mathrm{Sb}$ recombination frequencies of each recombinant chromosome for which more than ten replicate cultures were scored. The mean value for $G l_{c}$ is that obtained in previous experiments, and the value for $G l_{\mathrm{H}}$ is that obtained by pooling the values of the two $G l$ recombinants and $G l_{1 !}$

data is apparent in table 8: the $G l_{\mathrm{C}}$ chromosome has a mean recombination frequency of $0 \cdot 226 \pm$ $0 \cdot 007$, whereas the previous estimate was $0 \cdot 161 \pm$ $0 \cdot 004$. The $G l_{\mathrm{H}}$ chromosome, on the other hand, has maintained its value of $0 \cdot 25-0 \cdot 26$, which does not differ significantly from the values for the two $G l$ recombination chromosomes. (In later tests, this group of chromosomes is pooled.) It is difficult, therefore, to explain this change in the value of the $G l_{C}$ chromosome in terms of an environmental effect, and it seems probable that there has been a genetic change in the $G l_{\mathrm{C}}$ stock used in these experiments. (There is no evidence for any steady change in the value of $G l_{C}$ over the period of these experiments.) In view of this, no use of $G l_{C}$ as control is made in the following analyses, and the old value is displayed in fig. 2 . The standard errors and 95 per cent limits shown in table 8 and fig. 2 were obtained by pooling the within-chromosome sums of squares, on the angular transform scale, for each chromosome other than $G l_{\mathrm{C}}$ (941 df altogether), and using this to estimate the error variance. The standard error on the untransformed scale for a chromosome with a mean of $y$ on the transformed scale is given by multiplying the standard error on the transformed scale by $2 \sin y \cos y$, and the 95 per cent confidence interval is found by multiplying further by $1 \cdot 96$.

\section{Crossovers between $h$ and $G I$}

If this class of recombinant chromosomes, which comprises the $r u h G l, h G l$ and $r u h G l$ th st recombinants, is examined there is evidence for significant heterogeneity. Using the values for chromosomes with more than 10 replicates, the between-chromosome mean square on the transformed scale is 0.03570 , which gives an $F$ value of $2 \cdot 11$ ( 9 and $\infty \mathrm{df})$ when compared with the error mean square $(0 \cdot 01691), p<0 \cdot 05$. If the $r u h$ Gl th st 1 chromosome is omitted, $\mathrm{F}$ drops to 1.92 ( 8 and $\infty \mathrm{df})$, which is just below the 5 per cent critical value. If $r u h G l 35$ is omitted, which is the next highest chromosome, $F=0.91$, which is clearly non-significant.

The status of $r u h G l 35$ is therefore not entirely clear. Neither it nor ruhGlthst 1 differ significantly from the $G l_{\mathrm{H}}$ and the $G l$ recombinant chromosomes, whereas the group of other chromosomes have a significantly $(p<0.02)$ lower mean $(0 \cdot 221 \pm 0 \cdot 005$ compared with $0 \cdot 257 \pm 0 \cdot 014)$. It seems most likely that $r u h G l 35$ and ruh Gl th st 1 both result from crossovers to the left of a high recombination gene or genes located between $h$ and $G l$, but $r u h G l 35$ could simply be an outlier of the low recombination group. Out of ten chromosomes for which there is an adequate amount of data, either one or two are thus the product of a crossover between $h$ and the locus of the putative high recombination factor. Since the $h-G l$ map distance is 14.5 units, and the locus of $h$ is $26 \cdot 5$, the high recombination factor is located at $29.6 \pm 1.8$ on the genetic map, if the figure of $2 / 10$ is used. The absence of heterogeneity within the group of recombinants when the two highest chromosomes are omitted supports the hypothesis of a single high recombination gene between $h$ and $G l$. At any event, it is clear that the factor or factors concerned are located much nearer to $h$ than $G l$. The effect of the gene is approximately 0.037 recombination units, from the contrast of the low groups with the $G l_{\mathrm{H}}$ chromosomes.

\section{Crossovers in the region to the right of $\mathrm{Gl}$}

From the fact that the mean of the low group of $h-G l$ recombinants is significantly higher than that 
of the older assays of $G l_{C}(0.221$ compared with $0 \cdot 161)$, it seems likely that there is additional high recombination material either to the left of $G l$ and closely linked to it, or to the right of $G l$, or both. The existence of material to the right of $G l$ is confirmed by examination of the various types of crossover in this region (table 7 , right half). Although the mean square of the means of these chromosomes does not differ significantly from the error mean square, a Tukey-Kramer test (Sokal and Rohlf 1981, p. 245) of the range of chromosome means (the difference between $\mathrm{Gl}$ th st 72 and $\mathrm{Gl}$ st sre ca 72) reveals a significant effect; the ratio of the range to its standard deviation (on the transformed scale) is 4.27 for 6 observations ( $p<$ 0.05 ) (in this test the values for $G l$ sre ca 31 and 33 are pooled, and that for Glsreca 71 is omitted, in order to reduce inequality in sample sizes).

Removing $G$ l th st 72 reduces this heterogeneity in means to insignificance, which suggests that Glthst 72 is a genuine high-recombination chromosome. The Tukey-Kramer comparison of the $G l_{\mathrm{H}}$ chromosomes with the crossover chromosomes other than $G l$ th st 72 is significant $(4 \cdot 20$ for 6 observations; $p<0 \cdot 05$ ), confirming the suggestion of the existence of material to the right of $G l$. Furthermore, Gl st sre ca 72 is clearly a low-value chromosome $(t=2 \cdot 79, \mathrm{p}<0 \cdot 01$, for a comparison with the $G l_{\mathrm{H}}$ chromosomes). This shows that the high recombination factor or factors cannot be located between $G l$ and $t h$.

These data therefore demonstrate that the putative high recombination gene or genes are either located between $s t$ and $s r$, or to the right of $s r$. The evidence is unfortunately not conclusive on this point. If the recombination frequencies of Gl sre ca 31 and 33 are taken at face value, they are high and must have been produced by a crossover to the right of the high recombination gene. The slightly lower value of $G l$ th st 71 agrees with this interpretation. But it is not out of the question statistically that the Gl sre ca values are really low, and that the value for $G l$ th $s t 71$ is high. It is even possible that two factors may be involved, one between $s t$ and $s r$, and the other to the right of $s r$. If a single factor is assumed, and if $G l$ th $s t 71$ is low, then the effect of the gene is approximately 0.031 on the scale of recombination frequencies, comparing the mean of the group of low chromosomes with $G l_{\mathrm{H}}$. Out of four informative chromosomes, two involve a crossover to the right and two to the left of the high recombination factor, placing it at approximately $53 \cdot 0 \pm 4 \cdot 5$ on the genetic map. This calculation should obviously be regarded with scepticism.

\section{DISCUSSION}

We will consider the results of both this paper and Charlesworth and Charlesworth (1985) in the light of previous work on variation in recombination.

\section{The selection responses}

\section{Inconsistencies in selection responses}

Selection for increased or decreased recombination has been practised in several species, with variable results (Maynard Smith 1978, Chapter 5, Turner, 1979). In Drosophila melanogaster, for example, selection for increased recombination was successful in the experiments of Parsons (1958), Chinnici (1971 $a$ ) and Kidwell (1972a), but not in those of Detlefsen and Roberts (1921), Moyer (1964) and Valentin (1973a). Selection for reduced recombination was successful in the experiments of Detlefsen and Roberts (1921), Chinnici (197la), Kidwell (1972a,b), Valentin (1973a) and Abdullah and Charlesworth (1974), but not Acton (1961). A role of chromosome rearrangements cannot be excluded in the experiments of Detlefsen and Roberts. It is unclear to what extent these inconsistencies between experiments are due to differences in the markers used for assaying recombination, or to differences in genetic background.

The present series of experiments appears to be the first in which a systematic attempt has been made to transfer the marker genes onto a background derived largely from a natural population, using several replicate lines for the same selection regime. Nonetheless, a high level of inconsistency between replicates was observed (tables 1 and 2 of Charlesworth and Charlesworth, 1985): none of eight lines selected for decreased recombination (four for $G l-S b$ and four for $S b-S e r$ ) responded significantly, and only a single line out of eight (a $G l-S b$ line) responded to selection for increased recombination. It seems likely that the effects of random genetic drift may be important in obscuring responses to selection in these and other experiments; both Valentin (1973a) and Kidwell (1972b) obtained large changes in recombination frequencies of opposite sign to the direction of selection. The design of the selection scheme for reduced recombination used here (fig. 1 of Charlesworth and Charlesworth, 1984), and the related design of Kidwell (1972 b), both mimic selection for reduced recombination due to strong epistatic selection on a pair of polymorphic loci (Haldane, 1962); the design of the scheme of selection for 
increased recombination mimics the model of recombination modification in a fluctuating environment studied by Charlesworth (1976). Theoretical studies of these cases have shown that selection on genetic modifiers of recombination is generally weak unless there is close linkage between loci subject directly to selection and the modifiers of recombination (Nei 1967; Kidwell, 1972b; Charlesworth, 1976). In view of the evidence that both $\mathrm{X}$ and 2 nd chromosomes contribute significantly to the increase in recombination between the 3rd chromosome genes $G l$ and $S b$ (table 2), it is thus not surprising that consistent responses to selection have not been obtained. The failure to obtain a renewed response to selection on its resumption after relaxation (Charlesworth and Charlesworth, 1985, third section) could also be due to chance rather than lack of variation.

The strong epistatic interactions observable in table 2 also probably limit the efficiency of selection; for example, the effect of the high chromosome 3 genes on a low background of $X$ and 2 nd chromosomes is only about 0.02 , whereas they have an effect of about 0.06 on a high background. The high 2 nd chromosome reduces recombination (when homozygous) except when the $\mathrm{X}$ and 3 rd chromosomes are both high. Inspection of table 2 in fact shows that it is impossible to go from the $\mathrm{C} \mathrm{C} \mathrm{C} \mathrm{state} \mathrm{to} \mathrm{one} \mathrm{in} \mathrm{which} \mathrm{three} \mathrm{C}$ chromosomes have successively been replaced by $\mathrm{H}$ chromosomes, and to achieve a net increase in recombination, by a path in which each replacement of a $\mathrm{C}$ by an $\mathrm{H}$ chromosome results in an increase in recombination.

\section{Asymmetries in responses and dominance relations}

Several workers have reported asymmetrical responses to upward and downward selection, notably Dewees (1975) on Tribolium and Kidwell (1972a) on $D$. melanogaster, who both obtained significant upward but non-significant downward responses using family selection designs. (These are less subject to the limitations imposed on the efficiency of selection by the linkage considerations described above). Both Dewees and Kidwell found that the recombination value of the $F 1$ between selected and unselected stocks was close to the value for the latter, and suggested that the asymmetry of the selection response might have been caused by reliance on low frequency, recessive alleles for high recombination. There is evidence from several other species that naturally occurring variation in recombination is often due to recessive high recombination alleles, in contrast to recessive mutant alleles which usually decrease recombination (Baker et al., 1976); examples include Schizophyllum (Stamberg, 1969; Tang and Chang, 1974) and Neurospora (Catcheside, 1977, Chap. 4).

The existence of such recessive factors for inceased recombination is extremely interesting, since they are unexpected from the molecular point of view (Catcheside, 1977). Furthermore, the "hitch-hiking" class of models for selection for increased recombination frequently predict a higher rate of change in gene frequency for recessive high recombination alleles than for dominant ones (Strobeck et al., 1976; Charlesworth et al., 1977; Maynard Smith, 1978, Chap. 7). (This is due to the fact that a selectively-favoured recombinant gamete will always give a hitch-hiking effect to an allele for increased recombination if the latter is homozygous, whereas it has only a 50 per cent chance of being associated with the favoured gamete when heterozygous.) A predominance of recessive high recombination alleles in natural population would therefore provide evidence in favour of hitch-hiking models.

Unfortunately, both the results obtained here and the results of earlier studies rule out such a generalization about dominance. For example, intermediacy of Fl's between high and low recombination stocks has been observed in $D$. melanogaster (Chinnici, 197la,b) and in silkworms (Turner, 1979, Ebinuma and Yoshitake, 1981). The interpretation of the $\mathrm{Fl}$ between our $\mathrm{H}$ and $C$ stocks with respect to $G l-S b$ recombination in complicated by the existence of the reciprocal effect, since the cross $\& \mathrm{C} \times \mathrm{H} \delta$ is often only slightly higher in recombination frequency than the value for the $\mathrm{C}$ stock, whereas the cross $q \mathrm{H} \times$ $\mathrm{C} \delta$ is always substantially higher (fourth section of Charlesworth and Charlesworth, 1985). Studies of the dominance effects of individual chromosomes on controlled genetic background (third section of this paper) clarify the situation, however. The $\mathrm{X}$ chromosome from the $\mathrm{H}$ stock is partially dominant on both $\mathrm{H}$ and $\mathrm{C}$ homozygous backgrounds with respect to the 2 nd and 3 rd chromosomes (tables 3 and 4 ). The $\mathrm{Gl}$ chromosome 3 from the $\mathrm{H}$ stock is capable of increasing recombination when heterozygous for a $\mathrm{C}$ chromosome 3 , on both $\mathrm{H}$ and $\mathrm{C}$ homozygous backgrounds of $\mathrm{X}$ and $2 \mathrm{nd}$ chromosomes (third section and table 6). This is fully consistent with the data on the Fl's between the $\mathrm{H}$ and $\mathrm{C}$ stocks and on the female backcrosses, reported by Charlesworth and Charlesworth (1985, fourth section). Clearly, there is no evidence for 
consistently recessive effects of high recombination alleles on the $\mathrm{X}$ and $3 \mathrm{rd}$ chromosome.

The situation with respect to the 2 nd chromosome is confused by the existence of strong epistasis, as mentioned above. On a homozygous background of $\mathrm{C} X$ and 3 rd chromosomes, the 2 nd chromosome gene or genes has a dominant effect of reducing recombination (table 5), whereas it appears to have a dominant effect of increasing recombination on a homozygous background of $\mathrm{H}$ chromosomes (table 2). The male backcross data, however, suggest that the $\mathrm{H} 2$ nd chromosome has a negative, dominant effect on recombination or is underdominant when the $\mathrm{X}$ and 3 rd chromosomes are heterozygous $\mathrm{H} / \mathrm{C}$ (Charlesworth and Charlesworth, 1985, table 4). In this table, the comparison of $2_{\mathrm{H}} / 2_{\mathrm{H}}$ with $2_{\mathrm{H}} / 2_{\mathrm{C}}$ on an $\mathrm{H} / \mathrm{C}$ background is given by twice the contrast of genotype (4) with $\mathrm{H} \times \mathrm{C}$, and is equal to 0.049 (nonsignificant). The contrast of $2_{\mathrm{H}} / 2_{\mathrm{C}}$. with $2 \mathrm{C} / 2_{\mathrm{C}}$ (obtained from twice the difference between $\mathrm{C} \times \mathrm{H}$ and genotype $(5))$ is equal to $-0.050(p<0.01)$. This negative effect of chromosome 2 when heterozygous on a heterozygous background of $\mathrm{X}$ and 2 nd chromosomes explains the comparatively low value of the $\mathrm{F} 1$ recombination frequency in the $q \mathrm{CC} \times \mathrm{H}$ o cross, despite the dominant or partially dominant effects of the H X and 2 nd chromosomes.

The apparent asymmetry in selection response observed here (only upward selection for $G l-S b$ recombination being significant) cannot be readily explained by these findings on dominance. In particular, the fact that the 2nd chromosome gene or genes reduce recombination except when the $X$ and 3 rd chromosomes are homozygous for high recombination alleles suggests that it would be quite easy to obtain a downward response to selection if the population were initially predominantly $\mathrm{C}$ for the $\mathrm{X}$ and $3 \mathrm{rd}$ chromosome genes. It seems most likely that the differences between the selection lines are due to chance factors such as random loss and fixation of alleles by drift (cf. Falconer, 1981, p. 191.)

\section{Accumulation of lethals in downward selection lines}

As described by Charlesworth and Charlesworth (1985, third section), the downward selection lines for $G l-S b$ recombination showed evidence of having accumulated recessive lethal genes, which were linked to the markers and present in high frequencies within lines, although different lethals were present in different lines. A similar phenomenon was noted by Kidwell ( $1972 b$ ), who suggested that the lethals had accumulated by random drift within the chromosomal region around the markers that is maintained permanently heterozygous as a result of the selection procedure (cf. fig. 1 of Charlesworth and Charlesworth, 1985). Nei (1970) has modelled the process of random accumulation of deleterious recessive factors in permanent chromosomal heterozygotes, and it seems likely that this explains the results of Kidwell and ourselves.

\section{Genetic basis of the $\mathrm{H}-\mathrm{C}$ difference}

\section{Number of genes involved}

Where sufficiently detailed genetic studies of the basis of responses to selection on recombination have been carried out, it is usually found that several genes are concerned, (e.g., Chinnici, $1971 b$; Turner, 1979; Ebinuma and Yoshitake, 1981). An exception is provided by the work of Valentin $(1973 a, b)$, who showed that a recessive $3 \mathrm{rd}$ chromosome gene mei-l was responsible for the change in recombination frequency in his line. The results obtained by us clearly indicate that there are genes on all three major chromosomes concerned in the difference in $G l-S b$ recombination between the $\mathrm{H}$ and $\mathrm{C}$ stocks. The number of genes on each chromosome is less certain. The mapping experiment described in the fourth section shows that there are at least two 3 rd chromosome factors, one located between $h$ and $G l$, and the other either between $s t$ and $s r$ or to the right of $s r$ (cf. figs 1 and 2). The data on the $h-G l$ recombinant chromosomes is consistent with there being only a single factor in this region, but some minor additional factors cannot be excluded. The generally low $\mathrm{Gl}$ $S b$ recombination values of these chromosomes indicate that the high recombination gene or genes are located closer to $h$ than to $G l$, which is perhaps surprising in view of the fact that the intensity of selection is greatest for modifiers that are closely linked to the marker genes (fifth section): formally, the high recombination gene is placed about 11 map units to the left of $G l$. If the other gene is located between $s t$ and $s r$, then it could be close to $S b$ (fig. 1): its formal position is about 5 units to the left of $S b$. (The lack of crossing over in male Drosophila means that the effective recombination frequencies for the markers and the modifiers are half these values.)

There are no mapping data for the $X$ and 2nd chromosome genes, but some conclusions about 
the numbers of factors on these chromosomes may be drawn. In the first place, the highly specific pattern of interaction between the 2nd chromosome and the $X$ and 3 rd chromosomes, with the reversal of 2 nd chromosome effects described above, is very hard to understand if there is more than one 2nd chromosome gene. Secondly, tests for the segregation of the $X$ and 2 nd chromosome genes are provided by comparisons of the appropriate genotypes of the male and female backcrosses (Charlesworth and Charlesworth, 1985, tables 3-6). Due to the absence of crossing over in males, all chromosomes segregate as units in the male backcrosses, whereas recombination is permitted in the $X$ and 2 nd chromosomes in the female backcrosses. On the hypothesis of a single gene on each of the $X$ and 2 nd chromosomes, it is easily seen by inspection of tables 3 and 5 of Charlesworth and Charlesworth (1985) that the value of genotype 1 of the lst generation female backcrosses should equal the mean of the values for genotypes (6) and (8) of the male backcross; the values are $0.128 \pm 0.005$ and $0.113 \pm 0.006$ respectively, which are not significantly different. Similarly, the mean of the values of genotypes 6 and 8 of the 1st generation female backcrosses should equal the mean of genotypes (1) and (3) of the male backcrosses; the values are $0 \cdot 194 \pm$ $0 \cdot 005$ and $0 \cdot 190 \pm 0 \cdot 008$ respectively. Unfortunately, tests cannot be made using the other genotypes in these crosses because of the fact that sometimes no distinction was made between $S b_{\mathrm{H}}$ and $G l_{\mathrm{H}}$ in the male backcross experiments, whereas a clear difference between the two was found in the female backcrosses and other experiments on the isogenic $\mathrm{H}$ and $\mathrm{C}$ stocks (see next section below). Finally, genotypes 1 and 5 in the 2nd female backcrosses generation have significantly smaller values than genotypes 1 and 5 of the 1st generation (table 6 of Charlesworth and Charlesworth, 1985). In view of the evidence, described above, that $2_{\mathrm{H}} / 2_{\mathrm{C}}$ has a considerably lower value than $2_{\mathrm{C}} / 2_{\mathrm{C}}$ on an $\mathrm{H} / \mathrm{C}$ or $\mathrm{C} / \mathrm{C}$ background of $\mathrm{X}$ and $3 \mathrm{rd}$ chromosomes, the differences between the 1st and 2nd female backcross generations for genotypes 1 and 5 must provide an underestimate of one-quarter of the $\mathrm{H} / \mathrm{C}-\mathrm{C} / \mathrm{C}$ effect for the $\mathrm{X}$ chromosome; the joint estimate of this effect is $0 \cdot 096 \pm 0 \cdot 02$, which substantially larger than the estimate obtained from table $3(0 \cdot 019 \pm$ 0.006 for $C y^{+}$females and $0.034 \pm 0.007$ for $C y$ females). There is certainly no suggestion here that the segregation of the $X$ chromosome has been obscured by recombination.

\section{Differences between the $G I_{H}$ and $S b_{H}$ chromosomes}

As described in the third section, the $G l$ and $S b$ chromosomes of the isogenic $\mathrm{H}$ stocks differ considerably in their effects on recombination; there is in fact no evidence that the $S b_{\mathrm{H}}$ chromosome carries any genes for increased $G l-S b$ recombination. Since the $G l_{\mathrm{H}}$ and $S b_{\mathrm{H}}$ chromosomes are each descended from just a single chromosome of the appropriate type in the mass-cultured $\mathrm{H}$ stock, it is not necessarily the case that the high recombination 3rd chromosome genes were associated only with the $G l$ chromosomes of the original selection line. The partial decline of the 3 rd chromosome effect in the mass-cultured $\mathrm{H}$ stock (Charlesworth and Charlesworth, 1985, third section) unfortunately makes it difficult to determine the composition of this stock with respect to high recombination 3rd chromosome genes. However, indirect evidence that $S b$ chromosomes from the H stock at one time carried high recombination genes is provided by the absence of a difference between $S b_{\mathrm{H}} / G l_{\mathrm{C}}$ and $G l_{\mathrm{H}} / S b_{\mathrm{C}}$ flies in the Fl between the mass-cultured $\mathrm{H}$ and $\mathrm{C}$ stocks (Charlesworth and Charlesworth, 1985, fourth section, and in the male backcross experiment (Charlesworth and Charlesworth, 1985, fourth section). Together with the evidence for a decline in the 3 rd chromosome values after relaxing selection, this suggests that the mass-cultured $G l$ and $S b$ stocks derived from the selection lines originally contained high recombination genes associated with both the $G l$ and $S b$ genes, but that the stock was segregating for them. The failure to include any such genes on the $S b_{\mathrm{H}}$ chromosome isolated in order to form the isogenic stock is presumably fortuitous. (The only partial nature of the decline in value of the 3rd chromosome incidentally provides further evidence for the existence of more than one high recombination locus on this chromosome.)

\section{Genetic basis of the reciprocal effect}

As described by Charlesworth and Charlesworth (1985, fourth section), there is a significant reciprocal difference in the $\mathrm{Fl}$ between the $\mathrm{H}$ and $\mathrm{C}$ stocks, both mass-cultured and isogenic. On the scale of recombination frequency, the value of this effect is estimated as being about 0.015 . The female backcross experiment suggests that it is controlled by a grandmaternal effect of the nuclear genotype, most probably due to chromosome 3 . The factors responsible for this reciprocal effect seem to be 
present in both the $S b_{\mathrm{H}}$ and $G l_{\mathrm{H}}$ isogenic $\mathrm{H}$ stocks, since it is observed in $S b_{\mathrm{H}} \times G l_{\mathrm{C}}$ as well as $G l_{\mathrm{H}} \times$ $S b_{\mathrm{C}} \mathrm{F} 1$ crosses. In view of the fact that the $S b_{\mathrm{H}}$ chromosome 3 from the isogenic $H$ stock lacks high recombination genes, this evidence suggests strongly that the chromosome 3 factors responsible for the reciprocal effect are distinct from those detected in the assays of genic effects on recombination (tables 2, 6, 7).

The grandmaternal nuclear control of the reciprocal effect is reminiscent of the mode of inheritance of cytotype in the $\mathrm{P}-\mathrm{M}$ system of hybrid dysgenesis reported by Engels (1979a), although not exactly the same. Kidwell (1977) has shown that female recombination between $G l$ and $S b$ is elevated in P-M dysgenic crosses, so that it is possible that the reciprocal effect observed here tion when used as a maternal parent, in Fl crosses with the other stocks, although the highest level of male recombination obtained here is much lower than that reported for $P-M$ dysgenic crosses by Kidwell et al., (1977): $1.3 \times 10^{-3}$ compared with $7 \cdot 2 \times 10^{-3}$. The data in table 9 suggest that the $G l_{\mathrm{H}}$ stock produces increased recombination in $\mathrm{F} 1$ males when used as the female parent with either $S b_{\mathrm{C}}$ or $S b_{\mathrm{H}}$; the frequency of male recombination in the cross $q S b_{\mathrm{H}} \times G l_{\mathrm{C}}$ is also possibly increased compared with the $\mathrm{C} \times \mathrm{C}$ crosses $(\mathrm{p}<0.04$ on Fisher's exact test). The frequency of male recombination in the cross $S b_{\mathrm{H}} \times G l_{\mathrm{C}}$ is, however, significantly lower than in the cross $G l_{\mathrm{H}} \times$ $S b_{\mathrm{C}}\left(\chi_{1}^{2}=8 \cdot 37, \mathrm{p}<0 \cdot 001\right)$.

The most likely explanation of these results is that the $G l_{\mathrm{H}}$ stock has an $\mathrm{M}$ cytotype, and the

Table 9 Frequencies of male recombination between $G l$ and $S b$ in crosses between the $\mathrm{C}$ and $\mathrm{H}$ isogenic stocks

\begin{tabular}{|c|c|c|c|}
\hline $\mathrm{F}_{1}$ Cross & $\begin{array}{l}\text { No. of } \\
\text { Recombinants }\end{array}$ & $\begin{array}{l}\text { No. of } \\
\text { Individuals }\end{array}$ & $\begin{array}{l}\text { Frequency of } \\
\text { Recombination }\end{array}$ \\
\hline$q \quad 0$ & & & \\
\hline $\mathrm{C} \mathrm{C} G l_{\mathrm{C}} \times \mathrm{CCS}_{\mathrm{C}}$ & 0 & 9311 & 0 \\
\hline C. C $S b_{\mathrm{C}} \times \mathrm{CCGl}$ & 0 & 9089 & 0 \\
\hline $\mathrm{H} \mathrm{H} G l_{\mathrm{H}} \times \mathrm{H} \mathrm{HS} b_{\mathrm{H}}$ & 10 & 10108 & $9.89 \times 10^{-4}$ \\
\hline $\mathrm{H} \mathrm{H} S b_{\mathrm{H}} \times \mathrm{H} \mathrm{H} G l_{\mathrm{H}}$ & 2 & 4423 & $4.52 \times 10^{-4}$ \\
\hline $\mathrm{C} \mathrm{C} G l_{\mathrm{c}} \times \mathrm{H} \mathrm{H} S b_{\mathrm{H}}$ & 1 & 11850 & $8.44 \times 10^{-5}$ \\
\hline $\mathrm{H} \mathrm{H} S b_{\mathrm{H}} \times \mathrm{CCGl}$ & 2 & 8868 & $2.25 \times 10^{-4}$ \\
\hline $\mathrm{CCSb} b_{\mathrm{C}} \times \mathrm{H} \mathrm{H} \mathrm{Gl}_{\mathrm{H}}$ & 1 & 10734 & $9 \cdot 32 \times 10^{-5}$ \\
\hline $\mathrm{H} \mathrm{HGl} l_{\mathrm{H}} \times \mathrm{CCS} b_{\mathrm{C}}$ & 13 & 9876 & $1.32 \times 10^{-3}$ \\
\hline
\end{tabular}

The tests were carried out by crossing single $F_{1} G l / S b$ males to $c n b w$; rie females in vials. Most of the putative recombinant progeny were tested by crossing to $c n b w$; rie to check that they segregated for the markers they carried. All individuals tested appeared to be genuine recombinants. Clusters of more than one recombinant per culture were scored as a single event (these were very rare).

is due to a dysgenic effect. It is hard to test this hypothesis rigorously, because of the small size of the reciprocal effect, but some tests of the masscultured and isogenic $\mathrm{H}$ and $\mathrm{C}$ stocks with respect to $\mathrm{P}-\mathrm{M}$ dysgenesis have been carried out. Measurements of male recombination frequencies in $\mathrm{Gl}+$ $\mathrm{l}+\mathrm{Sb}$ males in the mass-cultured $\mathrm{C}$ and $\mathrm{H}$ stocks yielded values of $14 / 22,885\left(6.1 \times 10^{-4}\right)$ and $12 / 22,237\left(5 \cdot 4 \times 10^{-4}\right)$ respectively. This does not suggest any significant contribution of factors inducing male recombination to the difference in female recombination between these stocks, but does not exclude a contribution of hybrid dysgenesis to the reciprocal effect in the F1.

The results of male recombination tests of the isogenic stocks and crosses between them are shown in table 9 . These suggest that the $G l_{\mathrm{H}}$ stock induces elevated frequencies of male recombina- other three stocks are P. This is confirmed by tests using Engels' $s n^{w}$ allele, which is unstable in dysgenic crosses, mutating to wild-type and strong $s n$ alleles with high frequency (Engels, 1979b). Crosses of the four stocks of table 9 to $s n^{w}$ on a P nuclear background (stock supplied by Dr A. J. Leigh Brown) yielded instability of $s n^{w}$ only in the case of $G l_{\mathrm{H}}$ mothers. The P-M cytotypes of the stocks thus do not correlate perfectly with the pattern of reciprocal effects on female recombination, although it is clear that crosses involving $G l_{\mathrm{H}}$ as female parent will be dysgenic with $\mathrm{P}$ strains.

It is thus not possible to reach a firm conclusion with respect to the role of hybrid dysgenesis in causing the reciprocal effect on recombination in F1 females detected here; the evidence suggests that dysgenesis may be occurring in some crosses, but that it is not necessarily causally involved with 
the determination of the reciprocal effect. Reciprocal effects on recombination have previously been reported for $D$. melanogaster by Thoday and Boam (1956), Lawrence (1958), Kidwell (1972a), and Lüning (1983), and for Neurospora by Lamb (1971) and Landner (1974). In the studies of Thoday and Boam (1956) and Lüning (1983), cytoplasmic inheritance was implicated; Lüning also had evidence for non-cytoplasmic reciprocal effects. The other cases have not been investigated in detail.

\section{Conclusions}

The results reported here demonstrate that the IV natural population contains genetic factors that modify the frequency of recombination in the $\mathrm{Gl}$ $S b$ region of chromosome 3 . In the final paper of this series, we will show that other regions of the genome are also affected by these factors, so that the genes concerned are not highly specific for a very limited part of the Drosophila genome. We have shown that there are at least four genes concerned in the difference between the high selected stock and the control, and that they interact in a complicated fashion. There is no evidence for recessivity of the high recombination genes. A small part of the selection response (approximately $0 \cdot 015$, out of a response of $0 \cdot 10$, on the scale of recombination frequency) is due to a grandmaternal effect of chromosome 3. The results of this, and other studies of natural variation in recombination, show that the genetic control of recombination in eukaryotes is highly complex, and that the information obtained from mutant screening procedures provides only a partial picture of the range of genetic control.

Acknowledgements We thank Martyn Stenning, Joan West, and Doris Williams for technical assistance. This work was supported by grants from SERC (GR/A/1253.3) and the Nuffield Foundation.

\section{REFERENCES}

ABDUllah, N. F. AND CHARLESWORTH, B. 1974. Selection for reduced crossing over in Drosophila melanogaster. Genetics, 76, 447-451.

ACTON, A. B. 1961. An unsuccessful attempt to reduce recombination by selection Amer. Nat., 95, 119-120.

BAKER, B. S., CARPENTER, A. T. C., ESPOSITO, M. S., ESPOSITO, R. E. AND SANDLER, L. 1976. The genetic control of meiosis. Ann. Rev. Genet., 10, 53-134.

CATCHESIDE, D. G. 1977. The Genetics of Recombination. Arnold, London.
CHARLESWORTH, B. 1976. Recombination modification in a fluctuating environment. Genetics, 83, 181-195.

CHARLESWORTH, B. AND CHARLESWORTH, D. 1985. Genetic variation in recombination in Drosophila. I. Responses to selection and preliminary genetic analysis. Heredity, 54, 71-83.

CHARLESWORTH, D., CHARLESWORTH, B. AND STROBECK, C. 1977. Effects of selfing on selection for recombination. Genetics, 86, 213-226.

CHINNICI, J. P. 1971a. Modification of recombination in Drosophila. I. Selection for increased and decreased crossing over. Genetics, 69, 71-83.

CHINNICI, J. P. $1971 \mathrm{~b}$. Modification of recombination in Drosophila. II. The polygenic control of crossing over. Genetics, 69, 85-96.

DETLEFSEN, J. A. AND ROBERTS, E. 1921. Studies on crossing over. I. The effect of selection on crossover'values. J. Exptl. Zool., 32, 333-354.

DEWEES, A. A. 1975. Genetic modification of recombination rate in Tribolium castaneum. Genetics, 81, 537-552.

EBINUMA, H. AND YOSHITAKE, N. 1981. The genetic system controlling recombination in the silkworm. Genetics, 99, 231-245.

ENGELS, W. R. 1979a. Hybrid dysgenesis in Drosophila melanogaster: rules of inheritance. Genet. Res., 33, 219236.

ENGELS, W. R. 1979b. Extrachromosomal control of mutability in Drosophila melanogaster. Proc. Nat. Acad. Sci. USA, 76, 4011-4015.

FALCONER, D. S. 1981. Introduction to Quantitative Genetics. (2nd ed.). Longman, London.

HALDANE, J. B. S. 1962. The selection of double heterozygotes. J. Genet., 58, 125-128.

KIDWELL, M. G. $1972 a$. Genetic change of recombination value in Drosophila melanogaster. I. Artificial selection for high and low recombination and some properties of recombination-modifying genes. Genetics, 70, 419-432.

KIDWELL, M. G. 1972b. Genetic change of recombination value in Drosophila melanogaster. II. Simulated natural selection. Genetics, 70, 433-443.

KIDWELL, M. G. 1977. Reciprocal differences in female recombination associated with hybrid dysgenesis in Drosophila melanogaster Genet. Res., 30, 77-88.

KIDWELL, M. G., KIDWELL, J. F. AND SVED, J. A. 1977. Hybrid dysgenesis in Drosophila melanogaster: a syndrome of aberrant traits including mutation, sterility and male recombination. Genetics, 86, 813-833.

LAMB, B. C. 1971. Some details and effects of the premeiotic controls of recombination frequencies in Neurospora crassa. Genet. Res., 18, 255-264.

LANDNER, L. 1974. Genetic control of recombination in Neurospora crassa. III. Selection for increased and decreased recombination frequency. Hereditas, 78, 185200.

LAWRENCE, M. J. 1958. Genotypic control of crossing-over on the first chromosome of Drosophila melanogaster. Nature, $182,889-890$.

LUCCHESI, J. C. AND SUZUKI, D. T. 1968. The interchromosomal control of recombination. Ann. Rev. Genet., 2, 87120.

LÜNING, K. G. 1983. Genetics of inbred Drosophila melanogaster. X. Maternal and cytoplasmic effects on recombination. Hereditas, 99, 57-68.

MAYNARD SMITH, J. 1978. The Evolution of Sex. Cambridge University Press, London.

MOYER, S. E. 1964. Selection for modification of recombination frequency of linked genes. Ph.D. thesis, University of Minnesota. 
NEI, M. 1967. Modification of linkage intensity by natural selection. Genetics, 57, 625-641.

NEI, M. 1970. Accumulation of nonfunctional genes on sheltered chromosomes. Amer. Nat., 104, 311-322.

PARSONS, P. A. 1958. Selection for increased recombination in Drosophila melanogaster. Amer. Nat., 92, 255-256.

SOKAL, R. R. AND ROHLF, F. J. 1981. Biometry (2nd ed.) Freeman, San Francisco.

STAMBERG, J. 1969. Genetic control of recombination in Schizophyllum commune: the occurrence and significance of natural variation. Heredity, 24, 361-368.

STROBECK, C., MAYNARD SMITH, J. AND CHARLESWORTH, B. 1976. The effects of hitch-hiking on a gene for recombination. Genetics, 82, 547-558.

TANG, C. Y. ANI) CHANG, S. T. 1974. Variation in recombination frequencies in Schizophyllum commune and its genetic control. Aust. J. Biol. Sci., 27, 103-110.
THODAY, J. M. AND BOAM, T. B. 1956. A possible effect of the cytoplasm on recombination in Drosophila melanogaster. J. Genet., 54, 457-461.

TURNER, J. R. G. 1979. Genetic control of recombination in the silkworm I. Multigenic control of chromosome 2. Heredity, 43, 273-292.

VALENTIN, J. 1973a. Selection for altered recombination frequency in Drosophila melanogaster. Hereditas, 74, 295297.

VALENTIN, J. 1973b. Characterization of a meiotic control gene affecting recombination in Drosophila melanogaster. Hereditas, 75, 5-22. 